\title{
LA HISTORIA LITERARIA DE ESPAÑA DE LOS MOHEDANO: CONCEPTO, FINALIDAD Y PRIMEROS REPAROS
}

José CEBRIÁN

Cualquier crítico malintencionado del siglo XVIII en cuyas manos cayese el Plan, método y división de la obra que fray Rafael (1722-1787) y fray Pedro Rodríguez Mohedano (1725-1791) colocaron al frente del tomo primero de la Historia literaria de España (1766-1791)’, estimaría casi de inmediato que les cegaba la soberbia o la vanidad o que les faltaba poco para perder el juicio.

Tan magna y voluntariosa empresa pretendía abarcar, nada más y nada menos, «desde el tiempo en que pueda constar que [España] cultivó las letras, hasta el presente: el origen, los varios estados, alteraciones, aumentos y decadencias que ha experimentado en tan diferentes siglos y distintas denominaciones»². Teniendo en cuenta que el concepto de español aglutinaba en la época a cuantos nacieron en el solar hispano (hubiesen escrito en latín, en árabe o en cualquier otra lengua) se presentaba como un quehacer casi imposible, a todas luces, para dos hombres solos que no disfrutaban de amanuenses suficientes.

1 Historia litemaria de España, deste stu primera población hasta muestros dias. Origen, progresos, decadencia y restratación de la literatura española, Madrid, Antonio Pérez de Soto, 17661791, 10 tomos en 11 vols. Las tomos II (primer y segundo volumen) y III fueron impresos por Francisco Xavier García. Del IV al IX por Joaquín lbarra. El X, póstumo para fray Rafael, por la viuda de Ibarra. El tomo I se reimprimió en 1769 (Juan SEMPERE Y GLARINOS, Ensayo de una biblioteca española de los mejores escritores del reynado de Cartos III, Madrid, Imprenta Real, 1785-1789, 6 tomos, IV, pág. 67). Diez años más tarde Ibarra efectuó una tercera tirada (A. PALAU, Manual, XVII, 274.582).

2 Historia literaria de España, I, (1766), pág. LXXIII. 
que pensaban no escalimar comentarios, opiniones, conjeturas y digresiones, que habrían de sacar adelante un proyecto tan ambicioso lejos de los círculos culturales de la corte y que no contaban con el apoyo (ni con las bendiciones) de la Orden, Sin embargo, estaban tan ilusionados al principio que no albergaron dudas sobre su conclusión. Y tan esperanzados y seguros de sí mismos que llegaron a prometérsela a Carlos III, cuyo aliento y protección se materializó en una generosa ayuda de mil ducados anuales".

No rahe duda que los Mohedano desearon emular en su fuero interno la prestigiosa Bibliotheca Hispana (1672-1696) de Nicolás Antonio", cuya fama. había aumentado con el correr de la centuria, merced al proyecto de reedición del padre Rávago", y a la labor de rescate, valoración y edición de olras obras suyas emprendida por Gregorio Mayans ${ }^{\circ}$. En cierta medida, *los materiales y el fondo» eran similares, pero el plan de la Historia literaria de España obedecía ¿ «distinta raturaleza y composición " No podemos olvidar que la Ad lectorem praefatio puesta al frente de la Nowa era, en realidad, un discurso de historia literaria en clave apologética en el que el sabio hispalense señalaba «los autores capitales y los momentos fundamentales de la cultura y de la literatura de los dos grandes períodoss".

I sos autores de la Historia literaria de España tambión la vertebtaron en dos grandes partes. Años más tarde el abate Xavier I Lampillas (1731-1810) lıará lo propio en su Saggio storico-apologetico della levteratura spagnuola (17781781), aumque la disposición y el pretexto fuemon distintos ${ }^{10}$. I a primera o «es-

\section{Mbrel, Dedisatoria, s.f.}

«Si un andaluz escribió la Bibliotheca Española, ouros andaluces escriban lia IVistoriu lin ferarior de Espeuñus. Ibid, pág. I.XIII. Aunque, como veremos luego, tegían clarn ronsciencia de ser nbras plahoradas con método diferente.

- Antonio MESTRE (ed.), Gregorio Mayons y Siscar. Epistolario, D, Mayans y Martincz Pingntón, 3, Real Bibliofera y polítictz cnlumal, Valencia, Ayuntaniento de Oliva, 1989, págs. $26-27$

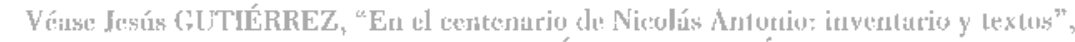
Dieciocho, VII, 1, (Ithaca, 1985) ), páks.s. 3-5, y Jesús P'ÉREZ MAGALLÓN, "('regorio Mayans en

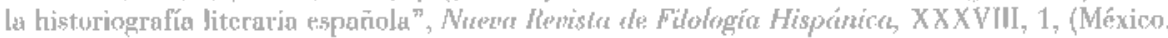
$1990)$, púgy. 249-251.

Historir literarin de Espenãa, I, páğs. LXIII.

* Gitaré por Bibliotheca Hispantr Novt, I, (1783)², pág. I-XV.

" Pedro SÁINZ RODRÍGLEZ, Historia de la rrísica literaria en España, Madrid, Taurus, 1989, pág. 67.

10 Afima I xapillas que en la parte de là *literatura antigua. (desde la antigüedad hasta el sigrlo XV) se linitará a las épocas y escritores que hayan sido objeto de inupugnaciones e intentará denestrau (ue "a ningunas letras debieron las letras antiguas rumanas quanto a las espanolas, exceptuadas las grjegas». La seguida parte, de la eliteratura modernas abarcará descle el siglo XV e 
tado antiguo» habría de comprender «todo el tiempo que corre desde la primera población de España hasta la renovación de las ciencias en Europa, acia el medio del siglo XV" ". La segunda o "estado moderno", arrancaría de la época de los Reyes Católicos y procurará llegar hasta «nuestros días y todo lo que va corriendo del siglo XVIII ${ }^{12}$.

En sus pretensiones totalistas, en su designio de ofrecer una amplia recapitulación de los saberes humanos, la Historia literaria de España habría de abordar cuanto perteneciese a «las letras, ciencias o estudios» ${ }^{13}$. Por consiguiente, se ocuparia también de

dar una exacta noticia de la vida de los sabios y escritores que han ilustrado esta nación, informar del mérito y contenido de sus obras con extractos o compendios, juicios y apologías de las principales y, finalmente, de todo lo que pueda conducir al pleno conocimiento de nuestra literatura en todos tiem-

inclurrá, con idénticos fines, «una brebe idea de la literatura española del siglo diez y ocho». Cito por la traducción española, Ensayo histórico-apologético de la literatura española contra las opiniones preocupadas de algunos escritores modermos italinnos, Zaragoza, Blas Miedes, 1782-1786. 7 lomos, 1, ff. $7 \%-8 \mathrm{r}$.

"Historia literutia de Espä̈a, 1, pág. CIX. Se subdivitiría en cinco grandes apartados: desde los prineros ticmpos hasta la ćpoea del emperator Angustes desde Augasto hasta la llegada de los godoa; desde los godos hasta la eutrada de los árabes; tesde don Pelayo hasta la cópeca de Fernando III ol Santo y union de Castilla y León y deste Alfonso X al Sabio hasta mediados del sighto XV y unión de Castilla y Aragón. Nienlás Anterio, eome se recordará, habia dividido su magna Biblietheco en Vetus (deade la época de Angusto hasen finales del siglo XV) y Nota (desde el XVI susque ad pracsenteru diemp).

a) Misterio tizemario de Espeñ̃a, I. pág. CIX. El plan inicial contemplaba una división cronológiua cn tres partes: desde los Reyes Católicos hasta el reinaelo de Felipe III, "en que comenzó la decadencia del buen gusto"; resto del siglo XVII; y siglo XVII, desde Felipe V y erección de la Real Academia Española xhasta nuestros díasm.

13. De tal modo define el adjetivo Literario el Diccionario de Autoridades (Madrid, Francisco

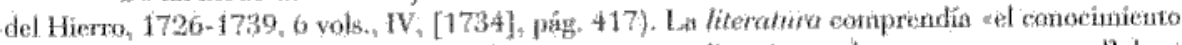
y cicncia de las letras (Ibideni). Sobre el concepto y su polisemia puede verse entre otros, Robert

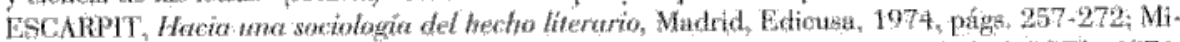
guel Ángel GARRIDO GALLARDO, Introducenón a ta teorín de la literature, Madrid, SCEL, 1976 , págs, 23-24; y Viror Manuel do ACUIAR E SI.VA, Tearia da literatura, Coimbra, Alriedira, 1984, I. págs. 1-13, caryas documentadas nòtas proporeionar bibliografia más detallada. Por lo que hace. A su concepto y alcance en el aiglo XVIl, véase Emilio PALACHOS FERNANDEZ. "Ilustuán y ti-

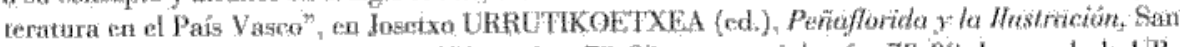
Schustián, Lniversidad de Deusto, 1986, págs. 70-80, en especial, pág. 78-80; Inmarulada LR-

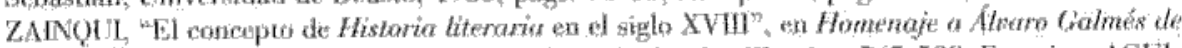
Fuentes, Madrid-Oviedo, Gredos/Lniveroidad, 1987, 3 vols. III prâg. 56.5-589; Francisco AGt1LAR PINAL, Intorducerion al siglo XVIt, Madrid, Júcar, 1991, pags. 182-188; Podro ALVAREZ DE MIRANDA, Patabras e ideas: el lexico de kn llustmaión tempmana en Espeña (1680-1750), Madrid. Real Acadenia Española, 1992, pügs, 430-454. Existe también una tesis de lięnciatura infétha que no be consultada: Guillermo DLAMANTE (COLADO, Literutura y conceptes afines en el sigla XhII (Estudio semântüo), Madricl. Univernidad Complutense, 1980. 
pos para desengaño e instrucción de la juventud española, gloria de nuestros sabios y crédito de toda la nación ${ }^{14}$.

Afanes y apetencias enciclopédicas, heredadas del humanismo renacentista, que hicieron declarar a los Mohedano, con más que ingenua candidez c inocencia, que desde sus años mozos se sintieron inclinados por «toda especie de literatura». Instruidos luego en latinidad y en filosofía escolástica, completaron su formación con el estudio de las obras del padre Fejion, los escritos de los diaristas y «la lectura de muchos excelentes libros» de Francia. Fstaban decididos a redactar una apología que habría de titularse Desagravio de la literatura española. En el discurir de sus páginas se habrían afunado en demostrar que el talcnto y la originalidad eran rasgos comunes a los españoles en todos los tiempos. Pero también era preciso que el discurso apologético persiguiera la instrucción de la juventud y el desengaño de los maestros que «manteniendo con tenacidad inflexible rancias preocupaciones, miran con desdén los nuevos descubrimientos e ignoran, o afectan ignorar, el feliz actual estado de las ciencias en Europa» ${ }^{15}$.

Prescindiendo de los afanes didáctico-apologéticos y del talante reformista que tantos disgustos les iba a ocasionar en el seno de su orden religiosa, hay en los Mohedano un interés por elaborar" «una historia crítica, seguida y methódica de nuestra literatura ${ }^{16}$, una preocupación sistemática por enjuiciar bajo supuestos racionales las obras y sus autores. No obstante, conviene recordar que el propio Mayans había declarado en sus Pensamientos literarios (1734) que fue él quien introdujo en España la historia literaria al redactar su Oración en alabanza de las eloqüentíssimas obras de Don Diego Saavedra Fajardo (1725), de intención encomiástica "pero verdaderamente crítica»" En la Rhetórica (1757), la define como el ramo de la naración historial, cultivado por "eruditos críticos», que selecciona y persigue el *conocimiento de los libros pará usar bien de ellos»:

La bistoria literaria refiere quáles son los lihros buenos i quáles log malns, su méthodo, chtilo i 11sw; los genios e ingenios de sus autores; los medios de pro-

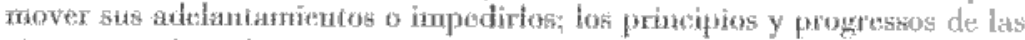
wisncias eruditas; las universidades literurias; las academias y sociedades de varias ciencias i el estado de la Jiteratura en ellas, i el ardelaratarniento o descuido de las naciones en cada gênero de ciencia ${ }^{19}$.

it Historia literaria de España, I, pág. I_XXIV.

15 hid., págs. VI-VIJ.

16. Hidl, pág. VII.

17 Antonio MESTRE SANGHIS (ed.), Gregorio Mayans y Siscar Obras complefas, Valen-

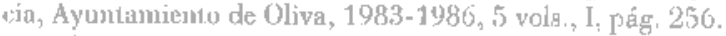

It Ibid., IIJ, pág, 623. 
Cierto que el articulista Louis de Jaucourt (1704-1779) había afirmado en la Encyclopédie (1751-1772) de Diderot y D'Alembert que para abundar en lo que realmente era literatura, sentida como avaste et agréable érudition", convenía minimizar a quienes no habían hecho más que arañarla, a los escritores superficiales desprovistos de erudición. Antes bien, convenía poseer un cabal conocimiento del mundo clásico, «puiser dans les sources de l'antiquité, la connoissance de la religion, de la politique, du gouvernement, des lois, des moeurs, des coutumes, des cérémonies, des jeux, des fêtes, des sacrifices et des spectacles de la Grèce et de la Rome» ${ }^{19}$. No obstante, como ha señalado con acierto I. Urzainqui ${ }^{20}$, el primer formulador térico de la necesidad de historiar las letras como tarea previa a todo progreso científico fue Francis Bacon (1561-1626) en su tratado De dignitate et augmentis scientiarum (1623), versión latina amplificada del original publicado en 1605 :

Argumentum non aliud est quam ut ex omni memoria repetatur, quae doctrinae et artes, quibus mundi aetatibus et regionibus floruerint. Earum antiquitates, progressus etian peragrationes per diversas orbis partes (migrant enim seientiae, non secus ac populi) rursus declinationes, obliviones, instaurationes commemorentur. Observetur sinul per singulas artes, inventionis occasio et origo; tradendi mos et disciplina; colendi et exercendi ratio et instituta. Adjiciartur etiam sectae, et controversiac maxime celebres, quae homines doctos tenuerunt; calumniae quibus patuerunt; laudes et honores quibus decoratae sunt. Notentur anctores praecipui, libri praestantiores, scholae, successiones, academiae, societates, collegia, ordines, denique omnia ruac: ad statum litterarum spectant ${ }^{21}$.

Las doctrinas de Bacon fueron recogidas en Europa por numerosos teóricos y ensayistas como Daniel Georg Morhof (1639-1691), en cuyo Polyhistor (1688) figuran comentadas y ampliadas ${ }^{22}$. Ya iniciado el siglo XVIII, Cibris-

19 Fncyclopédie on Dictionnaire ratsonné des Stipnces, des Arts ef des Métiens. Paris, 1751 -

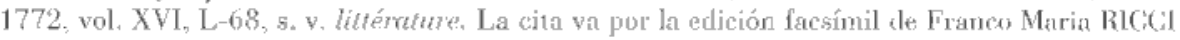
(Parma, 1970-1979, 18 vols.).

3D I. URZAINQUI, "El concepto de histonía lifrarin en el siglo XVIII", págs. 571-572.

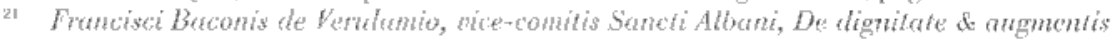
Scientiurum libri $X$, Lugduni Batavorum, Franciscum Moyarium \& Adrianum Wijngaerde, 1645, págs. 138-139. El abate Juan Anrlés (1740-1817) recueràa que fue Bacon quien dividió los saberes humanos en ures grandes categorias subordinadas a las facultades mentales, teoria que más tar de adoptaron los enciclopedistas: la hishorin, que pertenece a la memoria; la poesía, fruo de la ima ginueión; y la filosofia, obra de la razón (Dellorigine, progressi e stato attuale dogni letteruturu, Parma, Stamperia Reale, 1782-1790, 7 vols, I, pág. IlI).

2* Danielis Cporgi Morhofi Polythistor, sime de notitia aurtorum et rerum conmentari, Jubecae, Petri Böckmanui, 1688, págs. 9-21. Sobre los postulados de Bacon, págs. 9-10. Èsto mismo teoriza Burkhard Conthelf STRUVE en la Inboductio in notitiam reiliferarice et usum bibliothecarum, Francofurt et Lipsiate, Henticum L. Broennex, 1754, págs 43-51. La cita va por la edición adaptada a los nuevos tiempos por Johannes Cluristian Fischer. 
tophorus August Heumann (1681-1764) la definió en el Conspectus reipublicae litterariae (1718) como *historia litterarum et litteratorum, sive naIratio de ortu et progressu studiorum litterariorum ad usque nostram aetatem ${ }^{23}$. Fue a partir de entonces cuando empezó a arraigar en España la noción diacrónica y evolutiva de historia literaria. Lo que provocó discrepancias y una sonada polémica fue la diversidad totalizadora de materias, su pretendido alcance global y enciclopédico ${ }^{24}$.

$$
\text { ** } *
$$

A log Mohedano no se les pasaba por alto que su método historiográfico, cimentado en "la crítica, la legalidad y veracidad histórica» ${ }^{25}$, podía suscitar reacciones adversas e incomprensiones. En la parte concerniente al «estado antiguos de la Historia literaria de España aceptaron por comodidad el cómputo cronológico de los cuatro mil años para la época anterior al nacimiento de Cristo ${ }^{26}$, por ser «el nodo de contar más común entre los eruditos» ${ }^{27}$, pero desestimaron las supercherías mitológicas, los falsos cronicones (Dextro, Máximo, el falso Beroso, Julián Pérez) y aotros semejantes monsuruos», valiéndose. sólo de los textos estudiados, de «escritores veraces» coetáneos o próximos a los hochos y de las fuentes grecolatinas, sometidas ésias a "prudente desconfianza y maduro examen ${ }^{28}$. Todo ello con calculado rigor, con manifiesta equidistancia de la sátira y de la adulación y lisonja con sus juicios críticos.

Desde 1726, la «singular y tan celebrada» Biblioheca Hispana de Nicolás Antonio figuraba en el Diccionario de autoridades como excelso paradigma de. los «libros u obras de algunos autores que han tomado el assunto de recoger y

2.) Conspectus reiphblicae litterariae, sive via ad historiam litterariam iuventuti studiosae aperta e Christophory Augusto Henmanno, Hanoverae, Haeredes Nicolai Foersteri, 1746, pág. 1.

24 Luis Josef Velázquez (1722-1772), por ejemplo, ahorda en su tratado (considerado como la prinera historia de la poesía española) el apríncipio, origen, progresso y edades de la poesía castcllana desde el tienıpo en que nació hasta el presentew, estimando su origen y evolución cono fases previas para ordenar esta paute de la historia literaria. Origenes de la poesír castellona, Málaga, Francisco Maríne* de Aguilar, 1754, pág. 1 y 174. Véase J. SEMPERE Y GUARINOS, Ensayo de una biblioteca española, VI, págs, 139-149, y Philip DEACON, "Ja historia interna de los Origenes de la paesía castellana de Luis Jaseph Velázquez", Bolerist del Centro de Estadios del siglo XWM, VI, (Ovierlo, 1978), págs. 65-82.

2: Historín literaria de España, I, pág. CV.

26. Para Enrique Flórez (1702-1773), la división cronológica emás auturizada y clásica» era la de las famosas siete edades: las seis previas a Cristo y la posterior o cristiana, a En las duraciunts de las seis edades se incluyen los quatro mil años que los modernos señalan antes del nacimiento de Christon. Clave historial, Madrid, Antonio de Sancha, 17717, jágs, 4-5.

27 Historiz literaria de España, 1, págs.CIV.

24 Bid., págs, CV-CVI 
referir todos los escritores de una nación que han escrito obras, y las que han sido ${ }^{29}$. Las bibliotecas eran, en el sentir de los hombres de letras de la época, catálogos de autores y de obras; el armazón, en cierto modo, de los posteriores tratados enciclopédicos de historia literaria.

La Bibliotheca Hispana era para los Mohedano la más perfecta de cuantas se redactaron en Europa, pero de naturaleza y pretensiones diferentes a la Historia literaria de España. Sabían que el método novedoso que iban a emplear podía prestarse a equívocos, por lo que recalcaron con insistencia que no redactaban biblioteca, sino historia literaria. «No tanto pretendemos informar del número de autores, libros, versiones y ediciones como del contenido de las obras, de su calidad y del mérito de los que las escribieron ${ }^{30}$ :

Una bibliotheca no informa del origen, progresos, decadencia, causas, revoluciones y varios estados de las ciencias. La falta de enlace y orden de las noticias las priva de su mayor hermosura y claridad. En una bibliotheca se hace sólo una narración brevíssima de las vidas de los escritores; más bien se enumeran que se califican sus obras. El juicio es accesorio, el exameu breve [...] En muchos se forma sólo un simple cathálogo de sus escritos; no se hacen extractos, compendios ni de intento censuras o apologías de su contenido. Una bibliotheca no forma por su naturaleza un cuerpo histórico uniforme donde se vean coordinados los sucesos de las Letras, sus adelantamientos y atrasos en diferentes siglos ${ }^{31}$.

No sorprende demasiado que nuestros franciscanos indicaran en el Plan que fue en 1761 cuando tuvieron pensamientos de escribirla. Lo que extraña es su disimulado intento de hacer creer al lector que la Histoire littéraire de la France que los benedictinos de Saint-Maur habían comenzado a publicar en $1733^{32}$ llegó a poder de ellos tras haber redactado su prospecto y casi terminado el tomo primero. Basta leer el prefacio de los maurinos para comprobar que tan completa coincidencia «en el mismo pensamiento, en casi todo el método, plan y disposición ${ }^{33}$ se debía a algo más que a simple casualidad o coincidencia.

2) Diccionario de Autoridades, I, pág. 602, s. v. bibliotheca?

so Historia literaria de España, I, págs. C-CI.

${ }^{3}$ Ibid., pág. Cl.

32 Histoire littéraire de la France. Par des religieux bénédictins de la Congrégation de SaintMaur; Paris, Osmont, David y otros, 1733-1763, 12 vols. Los colaboradares, reunidos en la abadía parisina de Saint Cermaini-des-Prés, sólo pudieron llegar basta la mitad det siglo XII. Acusada de jansenista y de relajación convential, la orden fue suprimida definitivamente en 1790 por la Revolución. En el siglo XIX, la Acadómie des Inseriptions et Belles Lettres (Pastoret, Brial, Daunon, Amaury-Duval y otros) sacó a luz los tomos XIII al XXIII (Paris, Fermin Didot, 1814-1856). Véase el extenso texto de portada (confrontado a la de los Mohedano) en Óscar TACCA, La historia literaria, Madrid, Gredos, 1968, pág. 43, nota.

э. Historia literaria de España, I, págs, CX-CXI. 
Dom Rivet, dom Taillandier y sus colaboradores habían prometido documentar cuanto aseveraran con los textos de los autores originales ${ }^{3 *}$. La historia literaria de una nación debía comprender la totalidad de sus escritores, fuese cual fuese el vehículo lingüístico, el tema o la trascendencia de la obra. Sin embargo, habría de poner especial énfasis en ula connoissance des écrivains et la notion de leurs ouvrages ${ }^{* 5}$. Especificaron también que la Histoire littéraire de le France no podía confundirse con un simple catalogue des auteurs françois et des écrits qu'ils ont laissés en leur langue ${ }^{30}$, al modo de las bibliotecas de Latcroix du Maine (1584) o Verdier de Vauprivas $(1585)^{37}$;

Ce sont les montunents comnus de la littérature gauloise et françoise recherchés avec soin, réunis avec méthode, rangés dans leur ordre naturel, éclaircis avec une juste étendue, accompagnés des liaisons convenables, dont nous formons l'histoire littéraire de la France. On y aura un tableau vivant et animé non des faits d'une nation policée, puissante, belliqueuse, qui se borne à former des politiques, des héros, des conquérants, mais des actions d'un peuple. savant qui tendent à former des sages, des doctes, des bons citoyens, des fidèles sujets ${ }^{3 \mathrm{ta}}$.

Se trataba de un método analítico que trascendía lo descriptivo para ocuparse con detenimiento del trasfondo ideológico"

En su afán distintivo, los Mohedano introdujeron ciertas desemejanzas en la Historia literaria de España: la división de la materia en épocas, en lugar de narrar por siglos, que se agotan cuando se produce "alguna revolución o mudanza considcrable», y un mayor deterimiento en los pormenores de los tiempos antiguos ${ }^{40}$. Esto último les impidió progresar con la agilidad debida y, a la par, les obligó a perderse en alambicadas conjeturas sobre temas fútiles o de escasa relevancia. $\mathrm{Y}$, con el correr del ticmpo, se crigió en infranquable muralla.

$$
* * *
$$

Las halagüeñas expectativas por el «pronto despacho de un gran número de cxemplares» duraron poco tiempo ${ }^{21}$. En 1770 , cuarido apareció el tomo tercero, ya sabían que en deteminados cículos litcrarios madrileños la obra era

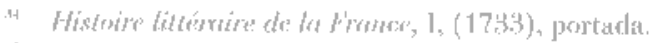

a) Hoid. pán. XI.

ti. Hoid, págr X XX.

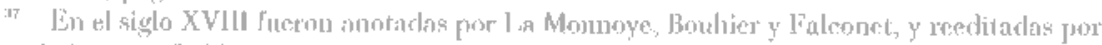

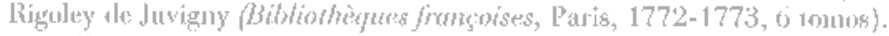

Hu Histore hilérate de le France, I, pág. XIX.

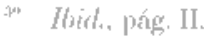

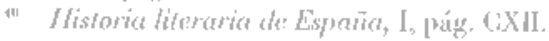

1) Sbid., II, 1, (1768), 5. 9. 
objeto de acaloradas censuras. Se veía con malos ojos tanta prolijidad en la narración del "estado antiguo». A quienes aguardaban con impaciencia que los nuevos tomos contuviesen detalladas biografías era preciso advertirles que «las vidas de los escritores son parte accesoria y sólo tienen entrada en quanto sirven para dar a conocer los sucesos de la literatura». Lo que de verdad importaba cran "los preparativos, las causas, los adjuntos y los efectos. En fin, todo lo que conduce a la noticia y estado de las Artes y las Ciencias»"2. A su entender, los primeros detractores no eran más que simples víctimas de «su oculta envidia y profunda ignorancia». Lejos de disminuir, los reparos arreciaban: la Historia literaria de España pecaba en su discurso de ampulosa y desmesurada. Para ellos eran impugnaciones de escasa credibilidad, cotilleos de tertulia "para mortificación de los literatos»:

¿Miscrable crudición la que carece de digresiones oportunas!, ique se contiene escrupulosa en sns límites!, ique tiene por hurto inexpiable coger una flor en las cercanías! ¡Seca, pálida, y sin vigor, como el rostro de un hambriento $o$ de in austero penitente!+3

Conviene subrayar que sobre Ralael Rodríguez Mohedano, el mayor de los hermanos, recayó casi todo el peso de la redacción, el grueso de la correspondencia literaria y la responsabilidad material de la obra. Su elección como provincial de la Orden el 7 de octubre de 1769, apoyada por frei Manuel do Cenáculo Vilas Boas (1724-1814), futuro arzobispo de Évorat+ y hermano de religión, le facilitó una serie de ventajas personales que hicieron mucho más viables sus quehaceres eruditos ${ }^{45}$. Sin embargo, el agustino fray Enrique Flórez había expresado en Granada su desaprobación y disgusto. La autorizada voz del autor de la España sagrada consideraba incompatible el gobiemo de la provincia y la elaboración de la Historia literaria de España. Lo mismo había repetido ante la comunidad franciscana de Alcalá la Real, en la jornada de retorno a Madrid y luego en la misma corte «a nuestros amigos y no amigos en varias ocasiones».

El 14 de septiembre de 1770 , los Mohedano le remitieron una extensa car-

t2. Ibid, III, (1770), f. 1r.-v.

*1 Ibid., IV. (1772), pág. V.

* Véase Francisco José de Gama (AEIRO, Frei Manuel do Cenáculo. Aspectos da sun actuañono filoséfica, Lisboa, Faculdade de Letras, 1959, y, sobre todo, J. MARCADÉ, Frei Manuel do Cenaculo Vilas Boas, évêque de Beja, archevêque d' Eora (1770-1814), Paris, Fondation Calouste Gulbenkian, 1978.

45. José Luis SOTO PÉREZ, Arabismo e llistración. Correspondencia literara de Fr: José Antonio Banqueri con Don Fr. Manuel det Cenáculo Vilas Boas, Obispo de Beja Y Atzobispo de Evora, Oviedo, Cátedra Feijoo, 1985 , pág. 25. 
ta desde el convento de San Antonio Abad de Granada. Intentaron demostrarle que el cargo no era un impedimento, sino todo lo contrario: en la visita provincial habían recogido libros raros y no pocos manuscritos que nos harían notable falta para continuar la obra». Pudieron comprar otros que, de haber sido meros "particulares", jamás habrían podido costear. Lograron hacerse de copiantes y amanuenses «de buena letra y ortografían. $Y$, por si fuera poco, consiguieron traerse a Granada «los mozos más hábiles e instruidos de la provincia [...] para que a nuestro lado se formen en los principios de la erudición " ${ }^{4}$. Por el contrario, ellos habían abogado en todas partes por el «mérito, la utilidad y desempeño de su obra; su método, su estilo y otras cosas en orden a su conducta que necesitaban de apologías ${ }^{48}$. Una meditada y desabrida refutación que conchúa acusando a Flórez de haber menospreciado los primeros tomos de la Historia literaria de España:

Vuestra Reverencia juzgó que la Historiu literaria de España no podia tener cosa digna de su atención hasta que llegase el siglo de Augusto. Nosotros no hemos sido tan desdeñosos con la España sagrada, pues aunque los primeros tomos en mucha parte sólo contienen principios gencrales de geografía y cronología, que no debíamos esperar aprenderlos por la obra de Vuestra Reverencia, los lémos enteramente [... Lo mismo decimos por lo que toca a la Clave historiat".

Ralael había escrito en 1768 una Respuesta ${ }^{50}$ contra quienes refutaron la extensión concedida a la antigua región cántabra ${ }^{51}$ en el tomo XXIV de la España sagrada $(1768)^{52}$, y dado años más tarde su opinión sobre tal controvessia (1773). De todas formas, es muy probable que el parecer adverso de Flórez

* Carta de los PP. R. Mohedana a Fi. Envigue Flórez], Granada, 14 de septiendure de 1770 , 7 hs. Real Academia de la Historia, Ms. 9-29-8-6049(11). Años después la publicaron en la Apologia del romo V de la Historia litesura de España, Madnid, Joaquín Ibaña, 1779, págs. 18-34, que es por donde citaré.

17 A un R.P.M. escritor, que consuró a los equtores haber admitido los empleos de su orden, en Apologia del tomo $\mathbf{F}$, pág. 29.

th Tbid., pág. 31.

th tbidl, págs. $32-33$

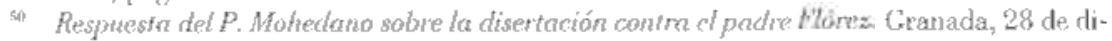
ciembre de 1768. Biblioceca Nacional, Ms. 2571, ff, 21,-27y. Su parecer (1773), en los lf. 28r,-131r.

51 Cabe recordar que Manuel de Larramendi (1690-1766), años antes, lo había sostenido en el Discurse hiscórteo sobre he antigua fomosa Canfabria (Madrid, Juan de Zúñiga, 1736). A similares intenciones apologéticas responde La Camtabrir nisclicada y demostrada (Madrid, Pedro Marín, 1779) de José Hipólito de Ozaeta.

s. España sagrada. Paste f. La Cantabria. Dissertación sobre cl sitio y extensión que turo en tiesupos de los romanos la región de los cántabros, Madrid, Antonio Marín, 1768 . Es el vol. 1 de] tomo XXIY. Hay cdición noderna de R. Teja y I. M. Iglesias-Gil, Santauder, Gabo Menor, 1981. 
animara a los enemigos de los Mohedano a abundar en él. En este trabajo sólo voy a ocuparme del primer revés serio que sufrieron los abnegados y voluntariosos autores de la Historia literaria de España, dejando para ocasión posterior el grueso de la agria y prolongada polémica en que se vio envuelta ${ }^{53}$.

El 3 de junio de 1774 fray Sebastián Sánchez, fray Tomás Pineda y otros hermanos de hábito concedieron en Granada censura favorable al tomo quinto de la Historia literaria de España, estimándolo «muy semejante a los anteriores en la erudición, la crítica y el ardor de promover las buenas letras y la gloria de la nación ${ }^{54}$. El Consejo de Castilla, por orden de 18 de noviembre, dictaminó someterlo al juicio crítico de Juan de Aravaca ( $\$ 1786)$, presbítero de la congregación del Salvador y académico de la Española desde $1767^{55}$.

El tomo quinto, cuyo prólogo data también de 1774, estaba organizado en dos libros: el IX, con la vida y escritos del erudito Cayo Julio Higino, liberto de Augusto ( 47 a. J.C.), polígrafo de saberes enciclopédicos estimado por Suetonio de origen hispánico. Y el X, que se ocupaba de varios oradores hispanolatinos, como Junio Galión, Quintiliano y, más en detalle, de la biografía y obra de Marco Porcio Latrón, paisano de Marco Anneo Séneca ${ }^{56}$.

EI 29 de diciembre, Aravaca remitió una muy injusta y desfavorable opinión de cuanto habían escrito los Mohedano ${ }^{57}$. Del primero aseveraba que sólo emitieron conjeturas: que era muy probable su naturaleza hispámica, y no de Alejandría; que era imposible averiguar el año de su nacimiento, defunción y entrada en la biblioteca de Augusto; y que se habían perdido sus obras, siendo dudosas las que figuraban a su nombre por ser originales de otro Higino del siglo V. De Marco Porcio Latrón, añadían poco más a lo que extractó Nicolás

59 Me ocupo de ella en los capítulos II-IV de La historia literaria en el siglo XVIII. En prensa.

st A.H.N., Consejos, leg. 5535 (5), dto. 2,

5 Véase Francisco AGUILAR PIÑA, Bibliografía de autores españotes del siglo XVIII, Madrid, C.S.I.C., 1981-1991, 6 vols. aparecidos, I, 2146-2160.

36 Véase Marcelino MENÉNDEZ PELAYO, Historia de las ideas estéticas en España, Madrid, C.S.I.C., 1974*, 2 vols., I, págs. 195-207. Más modernamente, han ponderado el rigor metodológico y crítico de los Mohedano -en referencia al tomo octavo (1781)-Antonio HOLGADO, "Una biografía falsificada de Columela", Anales de la Universidad de Cádiz, II, (Cádiz, 1985), pág. 313, y José Ignacio GARCÍA ARMENDÁRIZ, "Agricultura y agronomía en la obra de los PP. Rodríguez Mohedano”, Cuadernos de Investigación Histórica Brocar, XII, (Logroño, 1986), págs. 159-160.

57 A.H.N., Consejos, leg. 5535(5), dto. 3. Años más tarde, Ignacio López de Ayala (h. 1745 1789), oculto bajo pseudónimo, la reprodujo íntegra al final de su Carta misioa del doct. Fulgencio de Rajas i Peñalosa, Madrid, Isidoro de Hernández Pacheco, 1784, págs. 179-183. Vid. un breve resumen en Manuel SERRANO Y SANZ, "El Consejo de Castilla y la censura de libros en el siglo XVII", Revista de Archivos, Bibliotecas y Museos, XV, (Madrid, 1906), págs, 255-256. 
Antonio en la Bibliotheca Vetus. Por otra parte, en el sentir de Séneca, ya no existían en su época las tales declamaciones, siendo más bien elaboraciones suyas que en ningún modo podrían atribuirse a Latrón o a otros oradores. En consecuencia, era del parecer que

lexos de ser útiles a la instrucción de los jóvenes estudiosos, hacen por el contrario una demostración del mal gusto de estos declamadores, que viciaron y corrompieron la eloqüencia, haciéndola degenerar de la pureza, nervio y sublimidad a que la habían elevado Cicerón y los otros oradores, introduciendo las vanas sutilezas, afectariones y sofismas rpe nuestros autores (litro X, $\mathrm{X} 88$ ) dicen que no debían pasar aún en controversias fingidas y de nero exercicio ${ }^{5 P}$.

A los Mohedano debió dolerles en lo más hondo la alusión a la supuesta inutilidad didáctica de su obra, aunque es probable que lo que más les disgustara fuera la acusación de que no habían averiguado

documento ni noticia literaria importante que no se contenga en la Bibliotheca de don Nicolás Antonio, con la notable dilerencia de hallarse en ésta, con elegante soncisión, quanto hai digno de saberse de éstos y otros autores en solas quatro hojas y media, y ocupar la misma inateria todo el tomo quinto de la Historia literaria.

Aravaca todavía atizó aúm más las brasas de la invectiva al proponer un cálculo irónico de la cxtensión que cobraría la obra, caso de proseguir los autores con unas exposiciones tan impertimentes como farragosas:

Según cl método y cstilo que sus autores han observado en éste y en el antecedente tomo, no será exageración computar para ella hasta doce siglos de tiempo, y el material re siete a ocho mil volúmenes si han de completar hasta nuestros días las notirias de los literatos españoles ${ }^{(\alpha)}$.

El ensoberbecido académico no había comprendido (o pretendió ignorar aposta) el concepto y alcance de la nuevá historia literaria ensayada por los Mohedano, pues propuso que se limitara a un suplemento y adición a la Bibliotheca de don Nicolás Antonio», siendo de naturaleza y método distintos:

Hai sin duda mucho que añadir a la Biblosheca de don Nicolás Antonio, habićndose de 1ratar de todos los escritores y literatos de España que han florecido en la larga serio de diez y ocho siglos. Por esto, es mui digno fle la atención de los autores de nuestra Historic literatia el reservar sus investigaciones para los puntos más importantes y tocar con sobriedad los asuntos que

${ }_{5 \mathrm{~B}}$ Censura puesta al tomo quinto de lis Historia literaria de España, en C'asta misine del doct. Fulgencio de Projas, pág. 180.

5" Hờl, págs, 180-181.

(11) Shíl., pág. 181. 
nos interesan menos; y sobre todo dexarse de puras posibilidades, que hacen interminables las disputas y acostumbran a los genios cabilosos a un pirronismo universal. Falta tanto que investigar en nuestra historia literaria moderna que, en mi sentir, deben los que la escriben contentarse con lo que ya está comúnmente recibido acerca de los escritores antiguos, de quienes no producen algún tratado o documento nuevamente descubierto que sea útil al público y glorioso a la nación ${ }^{6 !}$.

Dictaminaba, en fin, que se redujeran las noticias sobre Higino, Porcio Latrón y los demás retóricos a "lo mui preciso i bien averiguado», que se omitiera la crítica del cuerpo de la obra y se restringiera a breves acotaciones marginales. Con criba tan sustancial, el tomo quinto podría dar cabida a la vida y escritos de Marco Anneo Séneca, de Columela y de otros miembros de la familia Annea ${ }^{62}$.

La licencia tardó en otorgarse, pero los Mohedano no cejaron en sus pretensiones. E1 24 de diciembre de 1776 dirigieron al Consejo una extensa y airada Carta, protestando de «los reparos puestos injustamente a una obra tan necesaria». Abogaron por su utilidad, proclamaron el «nuevo método, nueva facilidad, nuevas observaciones, nueva luz de crítica» de la Historia literaria de España y suplicaron

que los siguientes tomos de nuestra obra se remitan a hombres de inteligencia y buen celo [...] No a éste o a semejantes censores, declarados enemigos nuestros y de todos los que trabajan, pues han tenido por despreciables las obras de Feijoo y de Flórez, que son las mejores de la nación en este siglo, diciendo de aquélla que sólo contiene vejeces o novedades inútiles, y de éste que todo lo útil de su grande obra podía reducirse a dos cortos volúmenes ${ }^{63}$.

Apoyaron sus postulados con la entrega de un Catálogo de lo observado en el tomo quinto ajeno a la Bibliotheca de Nicolás Antonio ${ }^{64}$. En vista de todo ello, el Consejo acordó conceder la licencia de impresión el 23 de mayo de 1777 y archivar, por separado, la censura de Aravaca y la respuesta de los Mohedano. Fue una victoria airosa, pero trabajada y acaso pírrica. Había llegado la hora de jactarse por escrito de la derrota de sus contrarios:

Es natural que esta tropa de eruditos de moda se fastidie de obras sólidas, dilatadas y serias, pues jcómo han de tener paciencia para consumir un año en leer algunos tomos los que aspiran a ser eruditos en una semana? ${ }^{65}$

61 Ibid., pág. 182.

wiz Ibid., págs. 182-183.

a.H.N., Consejos, leg. 5535(5), dto. 4.

hat Fue incluido en la Apología del tomo V', págs. 311-347.

6.5 Historia literaria de España, V. (1777), pág. VII. 
Ahora bien, el pleito burocrático retrasó enormemente sus planes, pues replicaron a los reparos de Aravaca con una sólida, documentada y extensa Apología del tomo $V$ de la Historia literaria de España $(1776)^{66}$, cuya publicación en 1779 sirvió de espoleta para que la polémica estuviese servida. El displicente Aravaca no había sido capaz de entender o no había querido darse por enterado que la historia literaria, a diferencia de las bibliotecas, debía ocuparse también del «origen, progreso, decadencia y demás revoluciones» y de «los inedios y auxilios de promover las ciencias, de los impedimentos y estorbos que las han retardadon ${ }^{67}$.

Con fundada razón escribió Xavier Lampillas que el fin que le movió a escribir el Saggio storico-apologetico (1778-1781) no fue otro que $x$ defender a nuestra España de aquellas preocupaciones en cuya virtud es creída de muchos enemiga del buen gusto y corruptora de la literatura». Distaba mucho de pretender entregar al público una biblioteca y

mucho menos el formar la historia literaria de España, obra que tienen entre manos dos eruditísimos españoles, quienes nos han dado ya pirueba segura de su crítica y discernimiento en los quatro primeros tormos publicados, en que apenas han llegado al siglo de Augusto, lo que se debe atribuir a las curiosas investigaciones que han creído necesario hacer en orderı a la literatura y cultura de los españoles en los tiempos más remotos ${ }^{68}$.

Tal vez presumía en su fuero interno que la variedad de asuntos y el método expositivo podían dar al traste con la obra y dejarla inconclusa. Fue, a fin de cuentas, el presagio vaticinado años más tarde desde Italia (1782) por Juan Andrés:

Noi vediamo presentemente due fratelli Mohedani produrre una Storia letteraria dí Spagna di tale vastità che impossibile sembra, nonché difficile, che le fatiche di due nomini bastino a ridurla a compimento ${ }^{\text {iq }}$.

G6 Defensa de ha Historia Literaria de España]. [1776], 300 ff. Biblioteca Nacional, Ms. 12874. He citado completo el impreso en la nota 46.

6.7 Apologia del tomo V', págs. 63-634

(is Lisrayo histórico-apologético, I, (parte prínera), f. 7v. Lo vuelve a repetir en I, (parte segunda), pág. 15. Véase Miguel BATJLORI, La cultura hispano-italiana de los jesuitos expulsos (espoñoles-fisponoamericunos-filipisos) 1767-1814, Madrid, Gredos, 1966 págs. 37-41. Manfrer] TIETZ, "Zur Polemik un die spanische Literatur: Tiraboschi, Bettinelli und Llanpillas", en Stimment der Romania, Fesischriff fur W. Theodor Elweit zim 70 Geburtstag, Wiesbaden, Heymam, 1980, págs. 429-448; y P. SÁINZ RODRIGUEZ, Historin de la critica literutu, págs. 105-110.

(bell'origine, progressi e stato attuale, 1, (1782), pág. 484. 
Por aquel entonces, la encarnizada querella entre defensores y detractores de la Historia literaria de España (1766-1791) se hallaba en plena efervescencia. Y los Mohedano, a un paso de fracasar en sus ansiadas reformas culturales en una orden religiosa poco o nada afecta al racionalismo y a las Luces $^{70}$.

70. Véase el reciente estudio de Marie-Hélène PIWNIK, "Deux reformateur's éclairés au pilori: les frères Mohedano ", en Annie MOLINIÉ et al. (coords.), Mélanges offerts à Paul Guinard, Paris, Éditions Hispaniques, 1990-1991, 2 vols., II, págs. 181-189. 